\title{
Measurement of cultural competency: A pilot study of nurses' knowledge of religious practices
}

\author{
Kirsten A. Hickerson*1, Carly Fried ${ }^{2}$, Rochelle R. Levy ${ }^{2}$, Lisa M. Lewis ${ }^{1}$, Joseph Bernstein ${ }^{3}$ \\ ${ }^{1}$ School of Nursing, University of Pennsylvania, Philadelphia, PA, United States \\ ${ }^{2}$ Children's Hospital of Philadelphia, Philadelphia, PA, United States \\ ${ }^{3}$ Perelman School of Medicine, University of Pennsylvania, Philadelphia, PA, United States
}

Received: February 28, 2019

DOI: $10.5430 /$ jnep.v9n8p74
Accepted: April 14, 2019

Online Published: April 29, 2019

\begin{abstract}
Background: Most studies assessing cultural competence inquire about attitudes and beliefs and do not measure mastery of information. In this study, we investigate how much nurses know about various religious practices they might encounter.

Methods: An open response examination with 90 questions regarding Judaism, Islam, Hinduism, Mormonism, Seventh Day Adventist and Evangelical Christianity was administered to 24 faculty members and 60 students.

Results: The mean score on the exam was 22.8 out of 100 (students $23.3 \%$; faculty $21.6 \%$ ). The sub-scores were highest for questions about Judaism (mean 36.3\%) and lowest for questions about Hinduism (12.7\%). The answer "I don't know" was offered in response to $67.3 \%$ of all questions.

Discussion: Factual mastery by nurses regarding religious practices was seen to be low. Because providing culturally competent care demands nurses to be both willing and able, this preliminary finding suggests that delivering culturally competent care requires not only awareness and readiness but a better factual knowledge base.
\end{abstract}

Key Words: Cultural competence, Clinical education, Measurement tools, Cultural assessment, Nursing education, Religious competency

\section{INTRODUCTION}

Providing culturally competent care has been endorsed by nursing schools and organizations as a necessary aim of education and healthcare delivery. More than 40 years ago, Leininger ${ }^{[1]}$ urged nursing schools to integrate cultural education throughout the nursing curriculum. Further studies continued to emphasize the critical importance of teaching students to be culturally competent. ${ }^{[2-4]}$ National organizations such as the National League for Nursing ${ }^{[5]}$ and the American Association of Colleges of Nursing ${ }^{[6]}$ explicitly mandate that baccalaureate-nursing programs teach cultural competence. Hospital accrediting agencies likewise require health care institutions to demonstrate that they evaluate outcomes related to cultural competency. ${ }^{[7]}$

Papadopoulos ${ }^{[8]}$ proposed a model of cultural competence based on the synthesis and application of cultural awareness, cultural knowledge and cultural sensitivity. Despite the need for knowledge as a foundation for culturally competent care, studies in the literature tend to emphasize practitioners' beliefs and attitudes and not knowledge itself. ${ }^{[9-11]}$ And while correct attitudes are laudable, a strong knowledge base seems to be a fundamental, yet missing ingredient. ${ }^{[12,13]}$ Simply

\footnotetext{
*Correspondence: Kirsten A. Hickerson; Email: hickerso@nursing.upenn.edu; Address: School of Nursing, University of Pennsylvania, Philadelphia, PA, United States.
} 
put, before true culturally competent care can be delivered, there is a core body of knowledge that must be mastered.

Our preliminary review of the literature on cultural competency failed to reveal any assessments of factual mastery. Accordingly, a systematic search was undertaken to confirm that observation. We systematically reviewed CINAHL, Embase, PubMed and PsychINFO databases for papers reporting assessments of Cultural Competency in Nursing. We found 242 papers, yet there was not a single study in which mastery of factual knowledge was measured. Rather, self-assessed ratings of mastery were used. We thus proposed a study employing a test of factual mastery, using religion as the substrate.

\subsection{Background}

Knowledge of religious practices is one important component of culturally competent healthcare delivery. More than 90\% of Americans report that they believe in the existence of God or a universal spirit. ${ }^{[14]}$ More to the point, religious beliefs might influence health behaviors. ${ }^{[15,16]}$

Hence, nurses must be knowledgeable about their patients' religious beliefs and the ways in which these beliefs influence their health and health behaviors. To that end, the American Nurses Association ${ }^{[17]}$ and the Joint Commission on Accreditation for Healthcare Organization ${ }^{[7]}$ deem competency for registered nurses to include the consideration of religious beliefs in the development of plans of care.

Accordingly, the aim of the present study is to assess the extent of factual mastery of cultural practices that may impact healthcare. Specifically, in this study, we examined nurses' knowledge of religious practices in Judaism, Islam, Hinduism, Mormonism, Seventh Day Adventist and Evangelical Christianity. We further sought to discover whether there is any difference between the mastery levels shown by students compared to the mastery of faculty members.

Perhaps needless to say, knowledge of religious precepts is only a small aspect of culturally competent care; the religions we studied here are only a small fraction of those of practiced in the United States; and the questions we asked addressed only a small segment of the religions' possible interaction with healthcare. Nevertheless, this study could give rise to important findings if deficits of needed religious knowledge were to be found, as religious beliefs may influence health behaviors. ${ }^{[16]}$

\subsection{Research question}

What is the knowledge mastery demonstrated by nurse educators and nursing students regarding religious practices in Evangelical Christianity, Hinduism, Islam, Judaism, Mormonism, and Seventh Day Adventist Christianity?

\section{METHODS AND DESIGN}

This study was reviewed and approved by the Institutional Review Board. Identifying data for the participants was not collected.

\subsection{Study setting}

This cross-sectional study was conducted at an urban school of nursing in the Northeast of the United States. We distributed the online exam to all students in their last semester of their clinical year. We also tested all faculty who teach in required clinical courses. The clinical courses are those that have interactions with patients and can pose religious constraints for some students, for example contact with patients of the opposite sex, course assignments that are due during major or minor holidays, or requirements to work on the weekend.

\subsection{Intervention}

A 90-question examination about religious practices was constructed, asking about specific features of six mainstream religions: Judaism, Islam, Hinduism, Mormonism, Seventh Day Adventist and Evangelical Christianity. The topics of the questionnaire were chosen by the authors, based on personal experience, and in consultation with University Chaplains and with the nursing staff and house officers at the local Children's Hospital.

The topics included the following: the Sabbath; dress codes; dietary laws; religious holidays and their prescriptions; malefemale interactions; birth control; abortion; and gender identity. There were 15 questions (see Table 1). These questions were asked for all 6 religions, yielding a total of 90 questions.

The authors, in consultation with the University chaplains, developed an answer key.

The test was administered to a convenience sample of 84 examinees: 60 nursing students and 24 nursing faculty members. Student participants were recruited by posting on the school's internal website; a similar posting for faculty was placed on the internal website of the undergraduate course directors' special interest group.

The test was administered through Qualtrics (2018), an online survey tool. Data were collected anonymously. No demographic information was collected (i.e. we did not ask to which religion the examinee belonged, if any.) 
Table 1. Open ended questions applied to each of the 6 religions

\begin{tabular}{|ll|}
\hline 1) & What is the time of Sabbath of this religion? \\
\hline 2) & Please name an example of activity that cannot be done on Sabbath of this religion \\
\hline 3) & Please name an example of something that is customarily worn by a member of this religion \\
\hline 4) & Please name an example of something that may not be worn by members of this religion \\
\hline 5) & Please name an example of food forbidden in this religion \\
\hline 6$)$ & Please name an example of a food that is likely acceptable in this religion \\
\hline 7) & Please name a holiday of this religion and state its approximate time \\
\hline 8) & Please name a religious custom/duty on that holiday \\
\hline 9) & In this religion, can a female provider examine a male patient? \\
\hline 10) & In this religion, can a male provider examine a female patient without a chaperone? \\
\hline 11) & In this religion, can a female provider shake hands with male patient? \\
\hline 12) & In this religion, can a male provider shake hands with female patient? \\
\hline 13) & In this religion, can a member attend a clinic offering birth control? \\
\hline 14) & In this religion, can a member attend a clinic performing abortions? \\
\hline 15) & In this religion, can a member attend a clinic treating transgender patients by identified gender? \\
\hline
\end{tabular}

Examinees were instructed to provide their answers in open response form (that is, this was not a multiple-choice test); they were instructed to write "I do not know" if they knew that they did not know. The respondents were further instructed that leaving the question blank would be construed as if they had written "I do not know".

Two readers scored the test, as follows:

- the answer was correct;

- the answer was wrong; or

- the examinee indicated that he or she did not know the answer.

Correct answers received one point. Partial credit was given for partially correct answers. Both wrong answers and "I do not know" received the same score (that is, zero points) but the rate of indicating a lack of knowledge ('I do not know') was tabulated as well.

There were 22 instances among the 7,560 answers (90 questions multiplied by the 84 takers) where there was a discrepancy in the grade assigned by the graders to a particular response. The senior author resolved such discrepancies. The examinee received a score ranging from zero to a maximal $100 \%$. The reporting of scores was further broken down by individual religions and topics as well as examinee status (student vs. faculty).

\section{Results}

The mean score on this examination for all takers was $22.8 \%$. The sub-scores by denomination ranged from $12.7 \%$ (Hinduism) to $36.3 \%$ (Judaism). The mean score for nursing students was $23.3 \%$ compared to a mean of $21.6 \%$ for fac- ulty. The mean number of times (out of 90 question) "I don't know" was selected was $60.6(67.3 \%)$.

The mean score for questions pertaining to each of the six religions is shown in Table 2.

Table 2. Scores by religion

\begin{tabular}{ll}
\hline Name of Religion & Mean Score (percent) \\
\hline Evangelical Christianity & $28.3 \%$ \\
Hinduism & $12.7 \%$ \\
Islam & $26.4 \%$ \\
Judaism & $36.3 \%$ \\
Mormonism & $20.0 \%$ \\
Seventh Day Adventist & $13.3 \%$ \\
\hline
\end{tabular}

\section{DisCusSiON}

Education and training has been identified by Douglas et al., ${ }^{[18]}$ as one of the 12 universally applicable standards of practice for culturally competent care. In this study, we investigated the extent to which a cohort of nursing students and nursing faculty met that standard with regards to knowledge about religion. We found that our subjects demonstrated low levels of factual mastery. On average, examinees knew less than one-quarter of the material, and confessed ignorance in response to more than two-thirds of the questions posed.

These results dovetail with prior studies reporting that students and recent graduates of nursing programs feel ill prepared to provide religious and spiritual care to their patients and that nursing faculty members also feel insufficiently expert or inadequately trained to teach religious and spiritual content in the clinical and classroom settings. ${ }^{[19-26]}$ 
Our findings here provide insight as to why nursing students and faculty may not feel well-prepared: namely, they do not have sufficient knowledge about the different religious practices in which their patients may follow. Indeed, the literature identifies lack of knowledge as one of the major barriers to religious and spiritual care. ${ }^{[27]}$

\subsection{Implications}

The need to provide culturally competent care, according to Douglas et al., ${ }^{[18]}$ is grounded in a "framework of social justice"-that all patients should be treated equally-but goes beyond that: knowing the specifics of a patient's unique cultural attributes may help select therapeutic plans that are in consonance with those attributes and avoid those that may conflict. The provision of culturally competent care therefore depends on knowledge.

Religion is an undeniably important part of culturally competent care. The religious rules that are accepted by adherents of a particular faith might affect whether they follow recommendations regarding diet and lifestyle, specific therapies and reproductive health, among others. Religious factors may also influence whether a patient even seeks care for certain conditions or will be comfortable receiving care in certain settings or from certain providers. Religious practice may pervade all aspects of a patient's life. Indeed, in Judaism, the rules of practice are called the "halacha", meaning "the way to walk", just as religious systems in the Far East are organized around "tao", which also translates to "the path". That is, for many, religious rules describe how one is to act in everyday life, not just the details of ritualized practice.

\subsection{Limitations}

We have identified limitations to our work. To start, the inclusion of a religion on the test was arbitrary. Although the 6 religions chosen had been identified by the Pew report ${ }^{[28]}$ as important ones in America, there are no doubt other religions that could have been reasonably included instead. Further, we can make no claim that our topics were equally pressing for all of the tested religions. In fact, it is likely that some of the selected issues are more important for one group, and less important for another. For example, dietary rules may be more central to Judaism than to Evangelical Christianity, whereas for issues about sexual reproduction, the reverse may apply.

We further did not ask respondents about their own religious identification and practice. We note that the scores were highest for questions at about Judaism, which very well may reflect the demographics of our study group: we used a convenience sample at an urban, Northeast school of nursing, and different results might be found in a different location.
Administering our test online, without a proctor, is a potential weakness, as it is possible that examinees may consult source material when taking the exam. The very low scores suggest that this is not a relevant criticism.

The examination could be criticized for its lack of a rigorous answer key, or even for its assumption that (for some questions at least) there is a definitive correct answer. After all, many religions are characterized by schools of thought and interpretation, with various behaviors at once prescribed by some yet proscribed by others. That criticism, too, is mitigated by the fact that many respondents confessed to not knowing any answer - let alone the right one.

The general approach of testing facts and precepts as means to assess potential for providing culturally competent care can also be questioned. This was alluded to by Dreher \& MacNaughton ${ }^{[29]}$ in which they warned against the commission of an ecological fallacy - conflating a specific patient and the group to which he or she belongs. It is certainly the case that some individuals proudly affiliate with a religious group yet do not follow the standard rules of that group (assuming such a standard can even be defined). There are ostensibly religious Muslims who drink alcohol, seemingly devout Jews who use machinery on the Sabbath and selfidentified Christians willing to have an abortion. Thus, a nurse cannot possibly know the rules as they apply to a given patient. At best, the nurse can only know the categories of issues where religion may interact with healthcare. According to this line of thought, as long as a healthcare provider is aware of the broad topics that may have relevance -and is willing to broach the discussion- no lapse will follow. Still, the data here suggest that nurses know too little to initiate an informed conversation. Just as giving advice for rehabilitating a sports injury may require some factual knowledge of the sport played itself, some factual knowledge of religions may be necessary to giving culturally competent nursing care. Familiarity with enough specific facts may facilitate a general discussion outside of these specific facts.

\section{Conclusions/Future ReSEARCH}

Cultural competence, at least in terms of the cognitive mastery of facts about religions, was found to be poor. This fund of knowledge must be augmented by improvements in the education and testing of nurses, in all phases of their careers.

This study can serve as the basis for further research regarding factual cultural knowledge assessments. There are many other domains outside of religion that must be covered. Even within the area of religion, there are other religious groups that were not included here and additional practices and customs for the 6 identified religious groups that were not tested. 
These gaps can be filled in future studies.

Future work will also comprise creating needed teaching materials, tools and guidance for Health Care Educators. Methods to increase knowledge surrounding cultural competency will likely include interactive, case-based sessions, a specialized didactic course, virtual classrooms, simulation and continuing education. ${ }^{[30-32]}$ The teaching might also be more effective if culturally diverse faculty and students are recruited and retained. ${ }^{[23]}$

It is certainly laudable that nurses feel confident about cultural awareness and that they are eager to provide culturally competent care. ${ }^{[21,23]}$ Nonetheless, a good attitude, while cer- tainly necessary, is not sufficient. Factual mastery is needed as well. Our findings in context of other studies reveal, to paraphrase Mathew 26:41, "the spirit is willing, but the fund of knowledge is weak". Without remedying this deficit, it will be difficult to delivery optimal, culturally competent care.

\section{ACKNOWLEDGements}

The authors would like to thank Paula M. Agosto, RN, MHA, SVP and Chief Nursing Officer Children's Hospital of Philadelphia for her support.

\section{CONFLICTS OF INTEREST DisClOSURE}

The authors declare that there is no conflict of interest.

\section{REFERENCES}

[1] Leininger M. Transcultural Nursing: concepts, Theories and Practices. New York, NY: John Wiley and Sons.

[2] Oluwatoyin O, Vahlmu-Mkandawire L, Dreuziger S, et al. Preparing culturally safe student nurses: An analysis of undergraduate cultural diversity course reflections. Journal of Professional Nursing. 2018; a934: 245-252. https://doi.org/10.1016/j . profnurs . 2017 11.011

[3] Rew L, Becker H, Chontichachalalauk J. Cultural diversity among nursing students: Reanalysis of the cultural awareness scale. Journal of Nursing Education. 2014; 53(2): 71-76.

[4] Kardong-Edgren S, Campinha-Bacote J. Cultural competency of graduating US Bachelor of Science nursing students. Contemp Nurse. 2008; 28(1-2): 37-44. https://doi.org/10.5172/conu.673.2 8.1-2.37

[5] National League for Nursing. NLN research priorities in nursing education. National League for Nursing. Diversity and cultural competence: keystone to nursing education. 2012. Available from: http://www.nln.org/docs/default-source/nlnreports /summer15nlnreport.pdf?sf vrsn=2Published\%20Accesse d $\% 200$ ctober $\% 207, \% 202018$

[6] American Nurses Association Council on Cultural Diversity in Nursing. 2000. Available from: http: //ojin.nursingworld.org/MainMenuCategories/ANA Marketplace/ANAPeriodicals/OJIN/Columns/Ethics/Cul turalValuesandEthicalConflicts.aspx

[7] The Joint Commission. Advancing effective communication, cultural competence, and patient-and family centered care: A roadmap for hospitals. 2010. Oakbrook Terrace. IL Author.

[8] Papadopoulos I. Transcultural health and social care: Development of culturally competent practitioners. New York, NY: Elsevier Health Sciences. 2008.

[9] Lin CJ, Lee CK, Huang MC. Cultural competence of healthcare providers: A systematic review of assessment instruments. Journal of Nursing Research. 2017; 25(3): 174-186.

[10] Loftin, Hartin, Branson, Reyes, 2013; Loftin, C., Hartin, V., Branson, M., Reyes, H. Measures of cultural competence in nurses: an integrative review. The Scientific World Journal. 2013. https: //doi.org/10.1155/2013/289101

[11] Starr S, Shattell MM, Gonzales C. Do nurse educators feel competent to teach cultural competency concepts? Teaching and Learning in
Nursing. 2011; 6(2): 84-88. https://doi.org/10.1016/j.teln .2010 .12 .004

[12] Campinha-Bacote J. Cultural competence in nursing curricula: how are we doing 20 years later? Journal of Nursing Education. 2006; 45(7).

[13] Eche IJ, Aronowitz T. Evaluating cultural competence of pediatric oncology nurses at a teaching hospital: A pilot study. Journal of Pediatric Oncology Nursing. 2017; 34(6): 422-426. PMid:28660797 https://doi.org/10.1177/1043454217713452

[14] Lugo L, Stencel S, Green J, et al. U.S. Religious Landscape Survey Religious Beliefs and Practices: Diverse and Politically Relevant. Washington, DC: Pew Research Center. 2008.

[15] Koenig HG. Religion, Spirituality, and Health: The Research and Clinical Implications. ISRN Psychiatry. 2012; 33. https : //doi . or g/10.5402/2012/278730

[16] Krause N, Hill PC, Emmons R, et al. Assessing the Relationship Between Religious Involvement and Health Behaviors. Health Education Behavior. 2017; 44(2): 278-284. PMid:27387205 https: //doi.org/10.1177/1090198116655314

[17] American Nurses Association Council on Cultural Diversity in Nursing. 2000. Available from: http: //ojin.nursingworld.org/MainMenuCategories/ANA Marketplace/ANAPeriodicals/OJIN/Columns/Ethics/Cul turalValuesandEthicalConflicts.aspx

[18] Douglas MK, Pierce JU, Rosenkoetter M, et al. Standards of practice for culturally competent nursing care: 2011 update. Journal of Transcultural Nursing. 2011; 22(4): 317-333. PMid:21949061 https://doi.org/10.1177/1043659611412965

[19] McElroy J, Madigan CK, Smith-Miller CA, et al. Cultural awareness among nursing staff at an academic medical center. The Journal of Nursing Administration. 2016; 46(3): 146-153. PMid:26906519 https://doi.org/10.1097/NNA.0000000000000315

[20] Cone PH, Giske T. Teaching spiritual care - a grounded theory study among undergraduate nursing educators. Journal of Clinical Nursing. 2012; 22: 1951-1960. https://doi.org/10.1111/j.1365-270 2.2012.04203.x

[21] Flood JL, Commendador K. A. Undergraduate nursing students and cross-cultural care: A program evaluation. Nurse Education Today. 2016; 36: 190-194. PMid:26507449 https://doi .org/10.1016/ j.nedt. 2015.10.003 
[22] Giske T. How undergraduate nursing students learn to care for patients spiritually in clinical studies - a review of the literature. Journal of Nursing Management. 2012; 20: 1049-1057.

[23] Holland AE. The lived experience of teaching about race in cultural nursing education. Journal of Transcultural Nursing. 2015; 26(1): 92-100. PMid:24682320 https://doi .org/10.1177/10436596 14523995

[24] Jeffreys MR, Dogan E. Evaluating the influence of cultural competence education on students' transcultural self-efficacy perceptions. Journal of Transcultural Nursing. 2012; 23(2): 188-197. PMid:22052092 https://doi.org/10.1177/10436596114238 36

[25] Kardong-Edgren S, Campinha-Bacote J. Cultural competency of graduating US Bachelor of Science nursing students. Contemp Nurse. 2008; 28(1-2): 37-44. https ://doi .org/10.5172/conu . 673.2 8.1-2.37

[26] Ume-Nwagbo PN. Implications of nursing faculties' cultural competence. Journal of Nursing Education. 2012; 51(5): 262-268. PMid:22432533 https ://doi .org/10.3928/01484834-20120 323-01
[27] Taylor EJ. What is spiritual care in nursing? Findings from an exercise in content validity. Holist Nurs Pract. 2008; 22(3): 154-159. PMid:18453895 https://doi.org/10.1097/01. HNP.0000318 024.60775 .46

[28] Pew Research Center. 2019. Available from: https://www.pewf orum.org/religious-landscape-study/

[29] Dreher M, MacNaughton N. Cultural competence in nursing: Foundation or fallacy? Nursing Outlook. 2002; 50(5): 181-186. https : //doi.org/10.1067/mno.2002.125800

[30] Betancourt JR, Green AR, Carrillo JE. Owusu Ananeh-Firempong, I. Defining cultural competence: a practical framework for addressing racial/ethnic disparities in health and health care. Public Health Reports. 2016.

[31] Marzilli C. Assessment of cultural competence in Texas nursing faculty. Nurse Education Today. 2016; 45: 225-229. PMid:27568280 https://doi.org/10.1016/j.nedt.2016.08.021

[32] McMillan LR. Exploring the world outside to increase cultural competence of the educator within. Journal of Cultural Diversity. 2012; $19(1)$ 